\title{
Pigmented Squamous Cell Carcinoma of the Lower Back Skin: A Case Report and Review of the Literature
}

Koumoundourou Dimitra*, Zolota Vassiliki, Gkermpesi Maria and Scopa Chrisoula

Department of Pathology, University Hospital of Patras Rio, Greece

\begin{abstract}
Pigmented squamous cell carcinoma is a rare neoplasm arising mostly in mucous membranes or in sun-exposed skin. We describe a case of this tumor in a 70 year-old man who presented with a pigmented ulcerated nodule on his lower back. Microscopic examination revealed a squamous cell carcinoma (SCC) with atypical proliferation of cells with individual cell keratisation and keratin pearls' formation. Apart from the squamous cell carcinoma a population of cytologically bland dendritic melanocytes was also present, a process that has been described as tumor cell colonization. Differential diagnosis of pigmented SCC includes melanoma with pseudoepitheliomatous hyperplasia, pigmented metatypical basal cell carcinoma and squamomelanocytic tumor, a recently described combined tumor. A small number of cases of pigmented SCC have been referred in the literature mainly located in mucosal surfaces such as the oral and nasal cavity and the conjunctiva but also in sun-exposed cutaneous sites especially at the skin of the head. In the present study, a case of pigmented SCC arising in sun protected skin is described. The authors review the published literature and discuss the histologic differential diagnosis of pigmented SCC as well as the possible mechanisms of melanocytes' colonization in pigmented non-melanocytic malignant neoplasms.
\end{abstract}

Keywords: Pigmented; SCC; Skin; Case study

\section{Introduction}

Squamous cell carcinoma (SCC) is the second most common cutaneous malignancy with basal cell carcinoma being the most frequent. The large majority of SCC is actinic induced and the likelihood of an individual developing SCC is particularly related to the cumulative exposure to sunlight [1]. A great number of variants of squamous cell carcinoma exists, including clear cell, spindle cell, desmoplastic, acantholytic, mucoepidermoid/adenosquamous, verrucous and metaplastic, as well as keratoacanthoma [2]. On the other hand, melanocytes are neural crestderived cells usually located in the basal cell layer of the skin, hair follicles and squamous-covered mucosal membranes. These cells produce melanin, an insoluble pigment using tyrosine as a substrate and transfer it through their dendritic processes to the adjacent epithelial cells. Melanocytes' migration in the epidermis and survival depends on the presence of the tyrosine kinase c-kit and its ligand stem cell factor [3]. The ratio of melanocytes to keratinocytes. In the skin varies from 1:4 in the face to 1:10 in the extremities. There are several malignant neoplasms with melanin deposition such as bronchial carcinoids, endocrine carcinomas, thyroid medullary carcinomas, neuroectodermal tumors, breast carcinomas, ovarian teratomas, and hepatoblastomas [4]. A small number of cases (less than 40) of SCC which contain a population of non neoplastic melanocytes, called pigmented SCCs have been reported In the English literature $[5,6]$. Most of these neoplasms have been described on mucosal surfaces such as the oral and nasal cavity, the conjunctiva [7-18] and the uterine cervix [19], as well as on sun-exposed skin such as the head and neck region where 19 cases of pigmented SCC have been described until 2011 [6,2029]. In addition, a case of subungual pigmented SCC has recently been reported [30]. Some of the reported cutaneous pigmented SCCs have been associated with solar keratosis [4]. One of the cases reported at the scrotum, was associated with lentigo [31]. This case study describes a rare case of pigmented SCC arising from the skin of the lower back which was not associated with actinic damaged skin or solar keratosis.

\section{Case Report}

A 75 year-old white man presented at the outpatient surgery clinic with a black ulcerated nodule of the right low back region. The patient was a marble worker and his medical history was free of cutaneous or other malignancies. The nodule measured $3 \mathrm{~cm}$ in greatest diameter, was dome shaped, partially erosive and poorly demarcated. The lesion was present for more than three years and had gradually increased in size during the last three months. The tumor was clinically suspicious for melanoma and was completely excised with $5 \mathrm{~mm}$ free margins. Apart from malignant melanoma, the clinical differential diagnosis also included pigmented basal cell carcinoma and pigmented actinic keratosis. At the pathology lab we received a skin specimen measuring $7 \times 3.5 \times 1.5 \mathrm{~cm}$ with an ulcerated black coloured-nodule $3 \mathrm{~cm}$ in greatest diameter. The lesion was poorly demarcated and had rubbery consistency with solid cut surface. The resected specimen was fixed in $10 \%$ formalin and was embedded in paraffin. Microscopic examination of heamatoxylin and eosin stained histologic sections revealed a partially ulcerated tumor consisting of irregular downward proliferation of atypical keratinocytes with easily recognizable keratinisation, intercellular bridges and few keratin pearls (Figure 1). Tumor cells displayed moderate nuclear and cytoplasmic pleomorphism (Figure 2). In some areas the tumor showed more pronounced disorganization with remarkable nuclear hyperchromasia and pleomorphism and increased number of mitotic figures (including atypical ones) located both in the basal and suprabasal layer of the epidermis. The neoplastic keratinocytes were admixed with a large number of cells containing melanin pigment (melanocytes or melanophages) (Figure 3). Melanocytes were unevenly distributed in the periphery as well as in the center of squamous cell nests. The melanocytes were mainly dendritic in shape but some round melanocytes were also recognized. In the papillary dermis an inflammatory infiltrate rich in lymphocytes and plasma cells admixed with a small number of eosinophils was observed. Intermingled melanophages were also present among the

*Corresponding author: Koumoundourou Dimitra, Department of Pathology, University Hospital of Patras Rio, Achaia-26500, Greece, Tel: 00306932478414; E-mail:dimikoum@yahoo.com

Received December 30, 2014; Accepted January 27, 2015; Published January 30, 2015

Citation: Dimitra K, Vassiliki Z, Maria G, Chrisoula S (2015) Pigmented Squamous Cell Carcinoma of the Lower Back Skin: A Case Report and Review of the Literature. Pigmentary Disorders 2: 165 . doi: 10.4172/2376-0427.1000165

Copyright: (C) 2015 Dimitra K, et al. This is an open-access article distributed under the terms of the Creative Commons Attribution License, which permits unrestricted use, distribution, and reproduction in any medium, provided the original author and source are credited. 
Citation: Dimitra K, Vassiliki Z, Maria G, Chrisoula S (2015) Pigmented Squamous Cell Carcinoma of the Lower Back Skin: A Case Report and Review of the Literature. Pigmentary Disorders 2: 165. doi:10.4172/2376-0427.1000165

Page 2 of 5

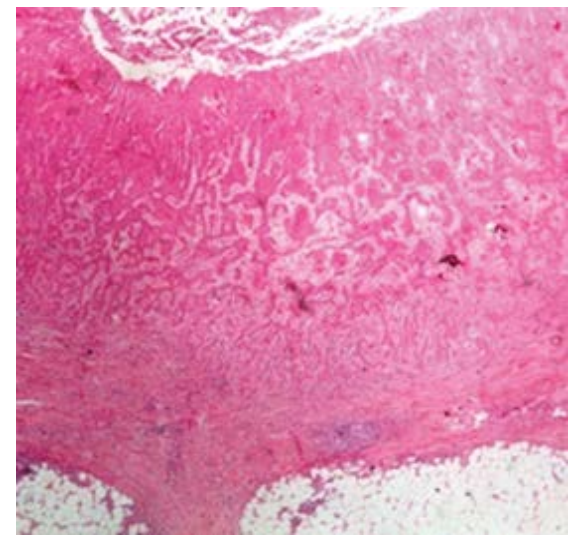

Figure 1: Microphotograph depicting the infiltrative growth pattern of the squamous cell nests.

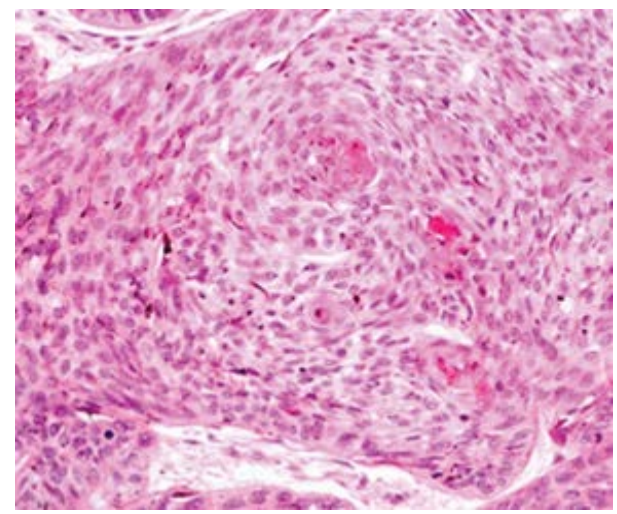

Figure 2: Atypical squamous cells with individual cell dyskeratosis.

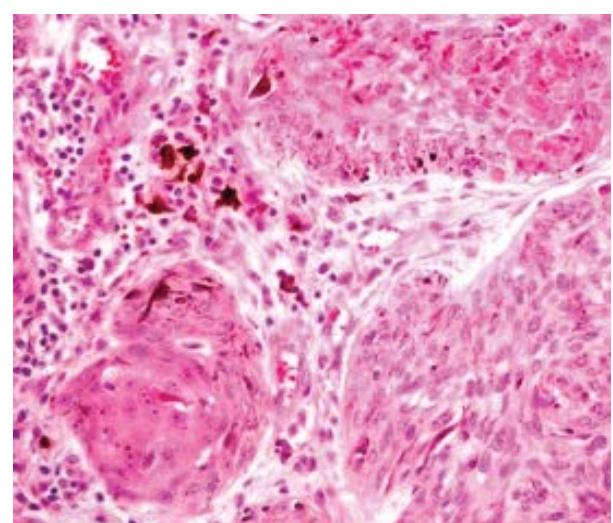

Figure 3: Presence of dendritic melanocytes in the basal layer of the epidermis. Melanophages colonize the surrounding stroma.

inflammatory cells. The greatest depth of tumor invasion (measured from the granular cell layer in areas of intact epidermis) was $0.5 \mathrm{~cm}$. The adjacent epithelium was moderately acanthotic while the underlying dermis showed no features of solar elastosis.

Based on tumor histology, pathological differential diagnosis included melanoma with pseudoepitheliomatous hyperplasia, pigmented metatypical basal cell carcinoma and (combined or collision) squamomelanocytic tumor. Immunohistochemical staining was additionally performed using the following antibodies: Pancytokeratins (AE1, AE3 ready to use, Cell Marque Corporation CA USA), high -molecular weight cytokeratins (34BE12 in a dilution 1:50 Dako, Denmark, A/F), p63 (a p53 homolog consistently expressed by basal stem cells of stratified epithelium, in a dilution 1:50 Dako, Denmark, A/F), S-100 (a calcium binding protein present in the nucleus and cytoplasm of neural crest derived cells, in a dilution 1:60 Biocare Medical, CA USA), HMB-45 (an oncofetal glycoconjugate associated with immature melanosomes, ready to use, Biocare Medical, CA USA), Melan-A, (a melanocyte associated marker not related with the melanosomes, in a dilution 1:40 Dako, Denmark A/F), and PGM1 (CD68, monocyte/macrophage derivation marker, in a dilution 1:80 Dako, Denmark, A/F). The malignant squamous cells were positive for AE1, AE3, 34BE12 (Figure 4) and p63 while the admixed melanin containing cells showed strong S-100, Melan-A (Figure 5) and HMB45 immunoreaction. PGM-1 revealed the population of melanophages mainly located in the papillary dermis (Figure 6). Since the overall tumor morphology and immunophenotype was consistent with a squamous cell carcinoma and the melanocytes appeared bland cytologically, having a dendritic shape and lacking nuclear peomorphism or hyperchromasia, the final diagnosis was that of a Pigmented Squamous Cell Carcinoma.

Staging processes showed no evidence of tumor dissemination. The patient underwent radiotherapy receiving $60 \mathrm{~Gy}$ in six weeks and 13 months after the tumor excision is well and alive without local recurrence or metastatic disease.

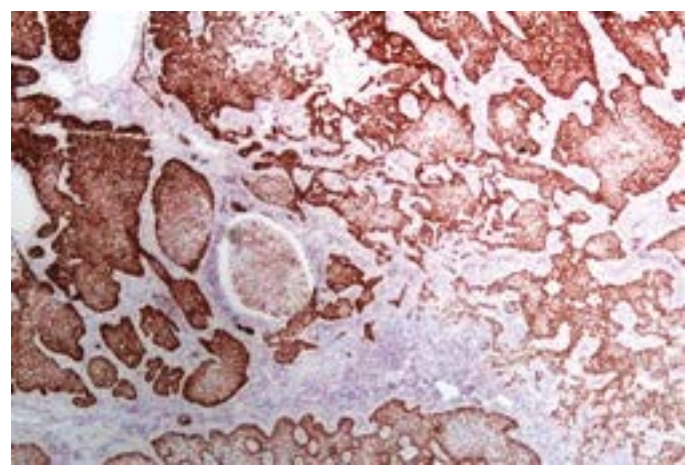

Figure 4: Neoplastic squamous cells showed intense immunohistochemical staining for High Molecular Weight Cytokeratins (34BE12).

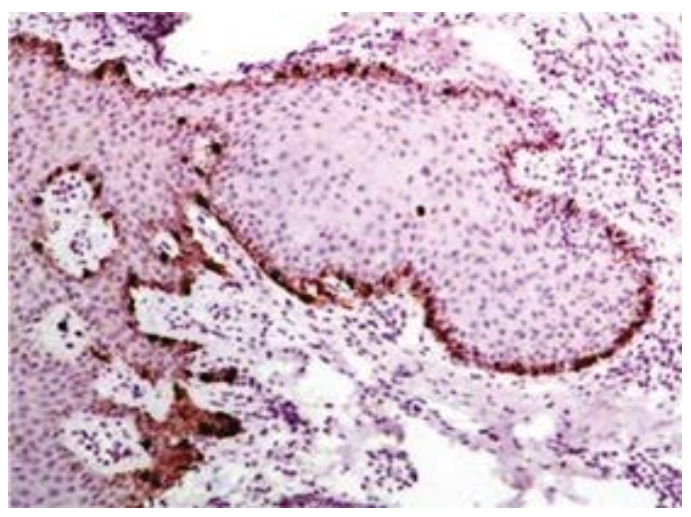

Figure 5: Positive immunoreaction of the epidermal melanocytes for melan-A 


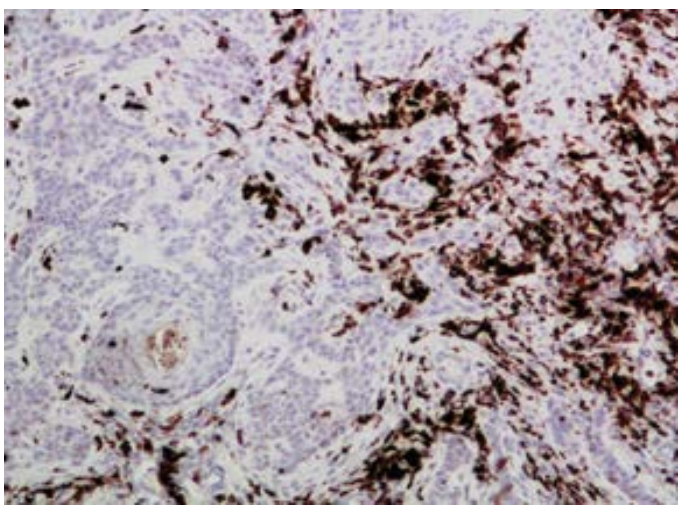

Figure 6: Immunohistochemical staining of melanophages for PGM-1.

\section{Discussion}

The present report describes an unusual case of pigmented skin tumor that fulfills the criteria for its inclusion in the category of pigmented squamous cell carcinomas. Other entities that were initially considered as alternative diagnoses were excluded after thorough examination of the morphology, review of the literature and evaluation of the immunostains. Melanoma with pseudoepitheliomatous hyperplasia is a neoplasm also showing an intimate admixture of melanocytes and keratinocytes but differs significantly from the tumor examined in the present study, because of the malignant nature of the melanocytes and the presence of a reactive in nature epithelial component as a response to the underlying malignancy (melanoma) Squamomelanocytic tumor is a combined tumor with a malignant epithelial and a melanoma component. Pigmented metatypical basal cell carcinoma is a tumor composed of basaloid cells characterized by peripheral palisading and stromal retraction. The mormphology of the present case was not consistent with a basal cell carcinoma. Moreover, tumor cells were positive for 34BE12 (High Molecular Weight CytoKeratin) and p63. Pigmented SCC is a very rare cutaneous neoplasm usually affecting mucosal surfaces or actinic damaged skin. In this case the lesion was located in the lower back skin, neither associating with mucous membranes nor with solar elastosis.

The presence of the melanocytes and melanophages was considered as colonization. The term colonization refers to the presence of a population of enlarged melanocytes with many dendritic processes randomly distributed within the squamous neoplastic cells. It is believed that the melanocytes' proliferation and colonization is stimulated by several cytokines and growth factors produced by the neoplastic squamous cells $[8,32]$. Chemotactic factors such as stem cell factor and endothelin-1 have been identified in cases of melanocytic colonization of the oral mucosa [33]. Other authors report that the pigmentation observed in cases of seborrheic keratosis is thought to derive through keratinocytes' endothelin-1 whose secretion is mediated by Tumor Necrosis Factor alpha (TNF- $\alpha$ ) and Endothelin Converting Enzyme 1a (ECE- 1a) [34]. Another hypothesis suggests that melanocytes present in non-melanocytic tumors derive from pluripotent stem cell proliferation [21,32]. However, this theory has not gained acceptance. This is due to the different histogenesis of melanocytes (neural crest) and squamous cells (ectoderm) and to the fact that melanocytes in pigmented squamous cell carcinoma show no features of malignant transformation.

Furthermore, in vitro studies support that melanocytes' activation is induced by TGF-beta produced by breast cancer cells [35]. Miteva et al. [36] proposed that melanocytes' colonisation is a process analogous to the epithelial hyperplasia observed overlying melanocytic lesions. In the present case, the possibility of a collision tumor (i.e a tumor consisting of two neoplasms identifiable in close proximity with one another) or a biphasic tumor (intimate admixture of two or more neoplasms intermingling closely within the same lesion) was also excluded. This was due to the fact that melanocytes showed bland cytologic features, dendritic shape and lack of cluster formation which is also a helpful diagnostic feature favoring a non-neoplastic process [37].

Such combined tumors with divergent squamous and melanocytic differentiation, recently described as squamomelanocytic tumors, have been reported in the literature $[36,38]$ in which both cell population (squamous cells and melanocytes) showed frankly malignant morphological and architectural features. In these tumors an origination from a subpopulation of stem cells capable of multidirectional differentiation cannot be excluded. Another theory for the histogenesis of combined tumors recently supported by some authors is the "interaction" theory [36]. According to this, a primary tumor may provoke the onset of a second neoplasm in the same lesion, by paracrine effects [39].

The melanocytes intermingled with squamous cells in the present case showed positive immunoreaction with HMB-45. It is well known that HMB-45 identifies an oncofetal glycoconjugate associated with immature melanosomes and is considered specific for activated or neoplastic melanocytes $[40,41]$. HMB- 45 positivity has been described in the majority of published cases of pigmented SCC [5,22-24,31,32] while other authors have reported absence of HMB- 45 immunoreactivity $[4,30]$. HMB-45 absence supports the non neoplastic nature of these melanocytes. However, its expression implies melanocyte stimulation and is considered a response to tumor's released antigens that promote melanocytes' activation [42].

In a previous report of a pigmented SCC of the scrotum [31] which was associated with a lentigo, it has been suggested that the melanocytes present in the lentigo were entrapped and activated during the squamous neoplasm enlargement, resulting in melanocyte colonization. Melanin deposition though rare in squamous cell carcinomas is a frequent finding in other skin malignancies such as basal cell carcinoma or in non-neoplastic skin lesions such as pigmented seborrheic keratosis (melanoacanthoma).

Melanin pigmentation has also been observed in some breast carcinomas mainly when tumor cell breach the dermal-epidermal interface $[43,44]$, so it was initially postulated that physical contact with the basal layer was required for colonisation to take place. However, due to the fact that it is also seen in neoplasms without evidence of epidermal disruption, it is believed that this melanin increase and "incontinence" may be associated with certain molecules' expression such as endothelin-1. On the other hand, pigmented non-melanocytic lesions have been reported without production of these factors [33]

Finally, it is known that hyperpigmentation appears normally in posttraumatic skin lesions as well as in cases of postinflammatory hyperpigmentation. Whether a similar mechanism can occur in malignant neoplasms needs to be further elucidated. In the present case the tumor was neither correlated with mucous membranes, nor was localized in sun-exposed skin and there was not a trauma history. In the lower back region there is no reported case of pigmented SCC. Rongioletti et al. referred a cutaneous squamomelanocytic tumor in the back region skin [45]. 
The biological behavior of pigmented squamous cell carcinoma is unclear because of the limited number of reported cases. Previous reports have not mentioned the biological aspect of this carcinoma type. However, it is believed that these neoplasms pursue a course similar to conventional SCC [4]. There are no clinical follow-up data in the majority of published cases [5,7-9,11-17,21-24,31] thus it is difficult to draw any definite conclusion. Morgan et al. [5] noticed absence of recurrence or metastases for an average of 4.2 years after tumor excision, while Matsumoto et al. [31] reported that only six from the patients with pigmented SCC that he studied had a follow up and were alive without recurrence or metastases for 5 months to 9.5 years after surgery. As far as squamomelanocytic tumors are concerned, the prognosis is worse, since these tumors have a more aggressive behavior similar to that of malignant melanoma. However, Pool SE refers no relapse or metastases for three patients with squamomelanocytic tumor for a mean follow up of 3.25 years [46,47].

Briefly, this is a case study of a cutaneous pigmented squamous cell carcinoma arising in the lower back skin. The authors support the theory of melanocytes' stimulation through growth factors and cytokines produced from the tumor cells. However, since this hypothesis has not been confirmed by immunohistochemical or molecular methods, the precise mechanism of melanocytes' colonization in these epithelial malignancies needs to be further investigated.

\section{References}

1. Johnson TM, Rowe DE, Nelson BR, Swanson NA (1992) Squamous cell carcinoma of the skin (excluding lip and oral mucosa). J Am Acad Dermatol 26: 467-484.

2. McKee PH, Calonje E, Granter SR (2005) Pathology of the skin with clinical correlations. 2: 1209

3. Haake A, Scott GA, Holbrook KA (2001) Structure and function of the skin: Overview of the epidermis and dermis. The biology of the skin. Parthenon Publishing, New York.

4. Terada T, Yamagami J, Fugimoto A, Tanaka K, Sugiura M (2003) Pigmented squamous cell carcinoma of the cheek skin probably arising from solar keratosis. Pathol Int 53: 468-472.

5. Morgan MB, Lima-Maribona J, Miller RA, Kilpatrick T, Tannenbaum M (2000) Pigmented squamous cell carcinoma of the skin: morphologic and immunohistochemical study of five cases. J Cutan Pathol 27: 381-386.

6. Rosendahl C, Cameron A, Bulinska A, Weedon D (2011) Cutaneous pigmented invasive squamous cell carcinoma: a case report with dermatoscopy and histology. Dermatol Pract Concept 1: 69-72.

7. Patakas B, Hecker R, Kramer HS (1974) Report on an oral, pigmented squamous cell carcinoma. Int J Oral Surg 3: 445-448.

8. Jauregui HO, Klintworth GK (1976) Pigmented squamous cell carcinoma of cornea and conjunctiva: A light microscopic, histochemical, and ultrastructural study. Cancer 38: 778-788.

9. Dunlap CL, Tomich CE (1981) Melanocyte colonization of oral squamous cell carcinoma. Oral Surg Oral Med Oral Pathol 52: 524-530.

10. Ide F, Kusuhara S, Ohnuma H, Miyake T, Nakajima T, et al. (1981) Pigmented squamous cell carcinoma of the oral mucosa - with special reference to the role of non-keratinocytes in tumors and tumorous conditions. J Nihon Univ Sch Dent 23: 1-9.

11. Salisbury JA, Szpak CA, Klintworth GK (1983) Pigmented squamous cell carcinoma of the conjunctiva. A clinicopathologic ultrastructural study. Ophthalmology 90: 1477-1481.

12. Adefule AO, Mordi VP (1983) Squamous cell carcinoma of the limbal conjunctiva with corneal involvement and racial melanosis in a Nigerian woman. Am J Ophthalmol 96: 106-107.

13. Modica LA, Youngberg GA, Avila FO (1990) Melanocyte colonization of an oral carcinoma. Histopathology 17: 477-478.

14. Kremer I, Sandbank J, Weinberger D, Rotem A, Shapiro A (1992) Pigmented epithelial tumours of the conjunctiva. Br J Ophthalmol 76: 294-296.
5. Kuwabara H, Uda H, Miyaguchi M, Nagai M, Saito K, et al. (1994) Pigmented squamous cell carcinoma of the alveolar ridge in the oral mucosa. Oral Surg Oral Med Oral Pathol 77: 61-65.

16. Yang J, Foster CS (1997) Squamous cell carcinoma of the conjunctiva. Int Ophthalmol Clin 37: 73-85.

17. Mathews A, Abraham EK, Amman S, Nair MK (1998) Pigmented squamous cell carcinoma of nasal cavity. Histopathology 33: 184-185.

18. Shields JA, Shields CL, Eagle RC Jr, Singh AD, Demirci H, et al. (2001) Pigmented conjunctival squamous cell carcinoma simulating a conjunctival melanoma. Am J Ophthalmol 132: 104-106.

19. Masuzawa N, Kishimoto M, Takahashi Y (2003) Pigmented squamous cell carcinoma of the uterine cervix. Int J Gynecol Pathol 22: 285-288.

20. Perez GL, Randle HW (1995) Natural history of squamous cell carcinoma of the skin: case report. Cutis 55: $34-36$

21. Kossard S, Cook D (1997) Pigmented squamous cell carcinoma with dendritic melanocytes. Australas J Dermatol 38: 145-147.

22. Jurado I, Saez A, Luelmo J, Diaz J, Mendez I, et al. (1998) Pigmented squamous cell carcinoma of the skin: report of two cases and review of the literature. Am J Dermatopathol 20: 578-581.

23. Kamiya M, Maehara R, lizuka S, Yoshida T, Yamanouchi H, et al. (1999) Pigmented squamous cell carcinoma with dendritic melanocyte colonization in the external auditory canal. Pathol Int 49: 909-912.

24. Chapman MS, Quitadamo MJ, Perry AE (2000) Pigmented squamous cel carcinoma. J Cutan Pathol 27: 93-95.

25. Ohnishi T, Nakai K, Nagayama T, Sasaki M, Suzuki T, et al. (2003) Pigmented squamous cell carcinoma of the skin. Report of a case with epiluminescence microscopic observation. Br J Dermatol 149: 1292-1293.

26. Zalaudek I, Citarella L, Soyer HP, Hofmann-Wellenhof R, Argenziano G (2004) Dermoscopy features of pigmented squamous cell carcinoma: a case report Dermatol Surg 30: 539-540.

27. Satter EK (2007) Pigmented squamous cell carcinoma. Am J Dermatopathol 29: $486-489$

28. Yoshida Y, Yamasaki A, Shiomi T, Suyama Y, Nakayama B, et al. (2009) Ulcerative pigmented squamous cell carcinoma in a 101-year-old Japanese woman. J Dermatol 36: 241-244.

29. Mikami T, Furuya I, Kumagai A, Furuuchi H, Hoshi H, et al. (2012) Pigmented squamous cell carcinoma of oral mucosa: clinicopathologic study of 3 cases. J Oral Maxillofac Surg 70: 1232-1239.

30. Ishida M, Iwai M, Yoshida K, Kagotani A, Okabe H (2014) Subungual pigmented squamous cell carcinoma presenting as longitudinal melanonychia: a case report with review of the literature. International journal of clinical and experimental pathology $7: 844$.

31. Matsumoto M, Sonobe H, Takeuchi T, Furihata M, Iwata J, et al. (1999) Pigmented squamous cell carcinoma of the scrotum associated with a lentigo. Br J Dermatol 141: 132-136.

32. Akasaka T (2002) Clinicopathology of the pigmented epidermal tumors. Nihon Hifukagakkai Kaishi 112: 1229-1240.

33. Satomura K, Tokuyama R, Yamasaki Y, Yuasa T, Tatehara S, et al. (2007) Possible involvement of stem cell factor and endothelin-1 in the emergence of pigmented squamous cell carcinoma in oral mucosa. J Oral Pathol Med 36 621-624.

34. Manaka L, Kadono S, Kawashima M, Kobayashi T, Imokawa G (2001) The mechanism of hyperpigmentation in seborrhoeic keratosis involves the high expression of endothelin-converting enzyme-1alpha and TNF-alpha, which stimulate secretion of endothelin 1. Br J Dermatol 145: 895-903.

35. Wilkins L, Gilchrest BA, Szabo G, Weinstein R, Maciag T (1985) The stimulation of normal human melanocyte proliferation in vitro by melanocyte growth factor from bovine brain. J Cell Physiol 122: 350-361.

36. Miteva M, Herschthal D, Ricotti C, Kerl H, Romanelli P (2009) A rare case of a cutaneous squamomelanocytic tumor: revisiting the histogenesis of combined neoplasms. Am J Dermatopathol 31: 599-603.

37. Florell SR, Zone JJ, Gerwels JW (2001) Basal cell carcinomas are populated by melanocytes and Langerhans [correction of Langerhan's] cells. Am J Dermatopathol 23: 24-28. 
Citation: Dimitra K, Vassiliki Z, Maria G, Chrisoula S (2015) Pigmented Squamous Cell Carcinoma of the Lower Back Skin: A Case Report and Review of the Literature. Pigmentary Disorders 2: 165. doi:10.4172/2376-0427.1000165

38. Rosen LB, Williams WD, Benson J, Rywlin AM (1984) A malignant neoplasm with features of both squamous cell carcinoma and malignant melanoma. Am J Dermatopathol 6 Suppl: 213-219.

39. Ahlgrimm-Siess V, Hofmann-Wellenhof R, Zalaudek I, Cerroni L, Kerl H (2007) Collision of malignant melanoma (lentigo maligna type) with squamous cell carcinoma in solar-damaged skin of the face. Dermatol Surg 33: 122-124.

40. Kapur RP, Bigler SA, Skelly M, Gown AM (1992) Anti-melanoma monoclonal antibody HMB-45 identifies an oncofetal glycoconjugate associated with immature melanosomes. Journal of Histochemistry \& Cytochemistry 40: 207212

41. Bacchi CE, Bonetti F, Pea M, Martignoni G, Gown AM (1996) HMB-45: a review Appl immune, 4:73-85

42. Smoller BR, McNutt NS, Hsu A (1989) HMB-45 recognizes stimulated melanocytes. J Cutan Pathol 16: 49-53.
43. Azzopardi JG, Eusebi V (1977) Melanocyte colonization and pigmentation of breast carcinoma. Histopathology 1: 21-30.

44. Mele M, Laurberg T, Engberg Damsgaard T, Funder J, Jensen V (2012) Melanocyte colonization and pigmentation of breast carcinoma: pathological and clinical aspects. Case Rep Pathol 2012: 427628.

45. Rongioletti F, Baldari M, Carli C, Fiocca R (2009) Squamomelanocytic tumor: a new case of a unique biphenotypic neoplasm of uncertain biological potential. J Cutan Pathol 36: 477-481.

46. Pool SE, Manieei F, Clark WH Jr, Harrist TJ (1999) Dermal squamo-melanocytic tumor: a unique biphenotypic neoplasm of uncertain biological potential. Hum Pathol 30: 525-529.

47. Ishida M, Iwai M, Yoshida K, Kagotani A, Okabe H (2014) Pigmented median raphe cyst of the penis with consideration of the possible mechanism of melanocytic colonization: A case report. Oncol Lett 7: 342-344. 